\title{
Differential Interferometric Measurement of Instability at Two Points in a Hypervelocity Boundary Layer
}

\author{
N. J. Parziale* \\ California Institute of Technology, Pasadena, California, 91125, USA \\ J. E. Shepherd ${ }^{\dagger}$ H. G. Hornung $\ddagger$ \\ California Institute of Technology, Pasadena, California, 91125, USA
}

\begin{abstract}
The focused laser differential interferometer (FLDI) was used to investigate disturbances in a hypervelocity boundary layer on a sharp five degree half-angle cone. The T5 hypervelocity free-piston driven reflected-shock tunnel was used as the test facility; in such a facility the study of thermo-chemical/fluid-dynamic energy exchange is emphasized. Two sensitive FLDI probe volumes were aligned along a generator of the cone that recorded time-traces of density fluctuation at sufficient time resolution, spatial resolution, and signal to noise ratio, so that the boundary layer instability could be resolved. This arrangement of the FLDI allows for the interpretation of disturbances at two points and the correlation between them. The acoustic instability is detected with narrow-band peaks in the spectral response at a number of frequencies $(500 \mathrm{kHz}$ to $1.29 \mathrm{MHz})$. The data indicate that the instability driving the boundary layer to turbulence is acoustic in nature. Preliminary analysis indicates that there is not a significant difference between $N_{2}$ and air acoustic boundary layer disturbance amplification factors for the representative cases presented. Computation of acoustic damping by thermo-chemical relaxation processes is presented for the same representative cases, and indicates that there is a negligible amount of absorption for both air and $\mathrm{N}_{2}$ at the observed disturbance frequencies.
\end{abstract}

\section{Nomenclature}

$h \quad$ Enthalpy, $(\mathrm{MJ} / \mathrm{kg})$

$P \quad$ Pressure, $(\mathrm{Pa})$

$U$ Velocity, $(\mathrm{m} / \mathrm{s})$

$T$ Temperature, (K)

Tv Vibrational Temperature, (K)

$\rho$ Density, $\left(\mathrm{kg} / \mathrm{m}^{3}\right)$

$\Delta \rho \quad$ Change in density, $\left(\mathrm{kg} / \mathrm{m}^{3}\right)$

$K \quad$ Gladstone-Dale constant, $\left(\mathrm{m}^{3} / \mathrm{kg}\right)$

$L \quad$ Sensitive Optical Path Length (m)

$\lambda$ Wavelength (nm)

$f \quad$ Frequency $(\mathrm{m})$

$M \quad$ Mach number

A Amplitude

$\delta \quad$ Boundary layer thickness $(\mu \mathrm{m})$

$\Delta \phi \quad$ Phase Change (Radians)

$s \quad$ Distance along cone surface $(\mathrm{m})$

$y \quad$ Wall-normal distance $(\mathrm{m})$

tau Time lag (s)

*PhD Candidate, Graduate Aeronautical Laboratories, 1200 E. California Blvd. MC 205-45, AIAA Student Member.

$\dagger$ Professor, Graduate Aeronautical Laboratories, 1200 E. California Blvd. MC 205-45, AIAA Member.

${ }^{\ddagger}$ Emeritus Professor, Graduate Aeronautical Laboratories, 1200 E. California Blvd. MC 205-45, AIAA Fellow. 
Subscript

$R$ Reservoir Condition

$\infty \quad$ Free-stream Condition

E Boundary Layer Edge Condition

$L$ Local Mean

$U$ Upstream

$D \quad$ Downstream

Unit Per unit length

\section{Introduction}

The study of boundary layer transition on hypersonic vehicles has been a subject of research for nearly 50 years because the surface heating rate and skin friction are several times higher when the boundary layer has transitioned from laminar to turbulent. Many types of ground-test facilities are used in the study of this research topic, one of which is the reflected-shock tunnel. The reflected-shock tunnel is used because of the ability to simulate hypervelocity flows; the study of thermo-chemical/fluid-dynamic energy exchange is emphasized in such a facility.

Much work on boundary layer transition has been conducted in the T5 Hypervelocity Shock Tunnel at GALCIT. ${ }^{1-7}$ Much of this work has focused on understanding high-enthalpy effects on transition Reynolds number on slender conical models at zero angle of attack. In Germain ${ }^{1}$ and Germain and Hornung, ${ }^{2}$ flow visualization (resonantly-enhanced shadowgraphy) results suggest that the transition mechanism at the conditions tested is the Tollmien-Schlichting instability. Alternatively, the effective use of an ultrasonically absorptive surface as a means of passive hypervelocity boundary-layer control in Rasheed ${ }^{5}$ and Rasheed et al. ${ }^{7}$ imply that the transition mechanism at the conditions tested is the acoustic instability. The need for direct measurement of the most amplified disturbances within a boundary layer on slender body in a shock tunnel is clearly evident in order to differentiate between potential instability mechanisms.

Fast response piezo-electric pressure transducers, heat-flux gauges, or hot wire anemometry techniques ${ }^{8-16}$ are traditionally used for the study of the instability on a slender body in hypersonic flow; however, the high frequency $(\approx 100 \mathrm{kHz}$ to $2 \mathrm{MHz}$ for conditions in T5) and small wavelength of the most strongly amplified disturbances render these techniques inadequate.

Optical tracking of turbulent spots in the boundary layer on a cone has been reported in $\mathrm{T} 5$ by introducing trace amounts of a seed gas with a strong line-strength (vaporized lithium) to the test gas, and focusing the spontaneous emission from a point of interest (the boundary layer) onto a fiber-coupled photodetector; ${ }^{17}$ this work was ultimately unsuccessful in measuring the boundary layer instability. Resonantly enhanced focused schlieren work in T5 yielded some promising results. ${ }^{18}$ Peaks in the spectral content at frequencies consistent with the acoustic instability were found along with detection of turbulent bursts; however, the method of resonantly enhanced focused schlieren makes quantitative interpretation of the results difficult.

Characterization of the free-stream noise in $\mathrm{T} 5$ was made with a focused laser differential interferometer. ${ }^{19}$ This non-intrusive optical technique was successfully implemented to make quantitative measurements of density fluctuations with high temporal $(25 \mathrm{MHz})$ and spatial $(700 \mu \mathrm{m})$ resolution. This work was continued by using the FLDI to make repeatable measurements of the acoustic instability at a single point in a hypervelocity boundary layer in $\mathrm{T} 5 .^{20}$

This paper describes an experimental campaign where the FLDI technique is used to investigate disturbances in a hypervelocity boundary layer on a sharp five degree half-angle cone at two locations. The two sensitive probe volumes aligned along a generator of the cone allow for the interpretation of disturbances at two points and the correlation between them. Distinct peaks in the spectral response at several frequencies (in a range of $500 \mathrm{kHz}$ to $1.3 \mathrm{MHz}$ ) are consistent with estimates of the acoustic instability; these narrowband peaks increase in amplitude and then broaden out in spectral response. The growth in amplitude and dramatic change in frequency content are consistent with departures from the laminar surface heating-rate, suggesting that the excitation and growth of the acoustic instability play an essential role in the transition process. The experimental setup and results are presented and discussed. 


\section{Facility}

All measurements are made in T5, the free-piston driven reflected-shock tunnel at the California Institute of Technology (Fig. 1). It is the fifth in a series of shock tunnels designed to simulate high-enthalpy real gas effects on aerodynamics of vehicles flying at hypervelocity speeds through the atmosphere. More information regarding the capabilities of $\mathrm{T} 5$ can be found in the literature. ${ }^{21}$

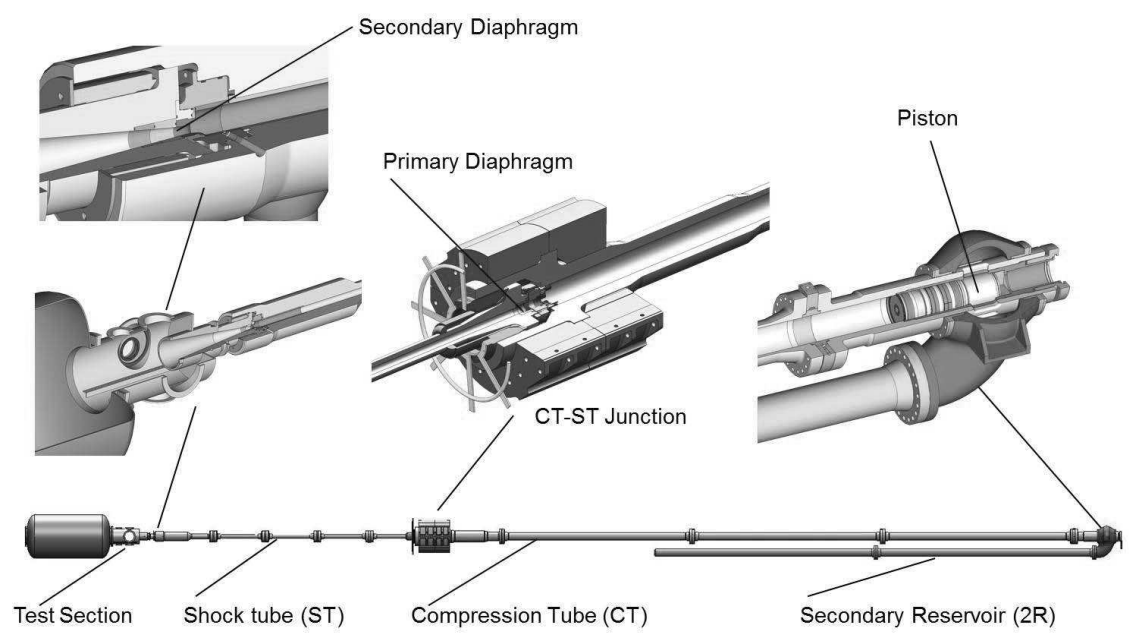

Figure 1. A schematic of T5 with a blown up view of each of the major sections.

An experiment is conducted as follows: a $120 \mathrm{~kg}$ aluminum piston is loaded into the compression tube/secondary reservoir junction. A secondary diaphragm (mylar, $127 \mu \mathrm{m}$ thick) is inserted at the nozzle throat at the end of the shock tube near the test, section and a primary diaphragm (stainless steel, $7 \mathrm{~mm}$ thick) is inserted at the compression tube/shock tube junction. The test section, shock tube and, compression tube are evacuated. The shock tube is filled with the test gas (in the present study, air and $\mathrm{N}_{2}$ to $40-120 \mathrm{kPa}$ ), the compression tube is filled with a He/Ar mixture to $\approx 50-100 \mathrm{kPa}$ and the secondary reservoir is filled with air to $\approx 2-10 \mathrm{MPa}$. The air in the secondary reservoir is released, driving the piston into the compression tube. This piston motion adiabatically compresses the driver gas of the shock tunnel to the rupture pressure of the primary diaphragm $(\approx 30-100 \mathrm{MPa})$. Following the primary diaphragm rupture, a shock wave propagates in the shock tube, is reflected off the end wall, breaking the secondary diaphragm and re-processing the test gas. The test gas is then at high temperature $(\approx 4000-9000 \mathrm{~K})$ and pressure $(\approx 20-$ $60 \mathrm{MPa}$ ) with negligible velocity, and is then expanded through a converging-diverging contoured nozzle to $\approx$ Mach 5.5 in the test section.

Measured primary shock speed and reservoir pressure are used to compute the reservoir conditions for each shot. Thermo-chemical equilibrium calculations are performed using Cantera ${ }^{22}$ with the Shock and Detonation Toolbox. ${ }^{23}$ The appropriate thermodynamic data are found in the literature. ${ }^{24,25}$

The steady expansion through the contoured nozzle from the reservoir to the free stream is modeled by the axisymmetric, reacting Navier Stokes equations as discussed by Candler ${ }^{26}$ and Wagnild. ${ }^{27}$ The boundary layer on the nozzle wall is assumed to be turbulent and modeled by one equation as in Spalart-Allmaras ${ }^{28}$ with the Catris-Aupoix ${ }^{29}$ compressibility correction. The grid is generated by the commercial tool, Gridgen. The mean flow over the cone is computed by the reacting, axisymmetric Navier Stokes equations with a structured-grid, and is part of the STABL software suite, as described by Johnson ${ }^{30}$ and Johnson et al. ${ }^{31}$ The boundary layer profiles and edge properties are extracted from the mean flow solutions during postprocessing.

\section{Measurement Technique}

Focused two-beam differential interferometry (FLDI) is the measurement technique applied in the present work (schematic in Fig. 2). This method was first applied to gasdynamics by Smeets and George at the French-German Research Institute of Saint-Louis (ISL) in the 1970's. ${ }^{32-34}$ To measure the acoustic instability on a slender body in a large scale reflected-shock tunnel (such as T5), five requirements are clear: 1) high 
temporal resolution to capture the high frequency of oscillation $(>10 \mathrm{MHz}), 2)$ high spatial resolution to capture the small wavelength of disturbance $(<1 \mathrm{~mm})$, 3) insensitivity to mechanical vibration, 4) the capability to have a small focal volume near the surface of the cone, and 5) a straightforward and repeatable means of extracting quantitative data from the technique. These requirements are met with FLDI.

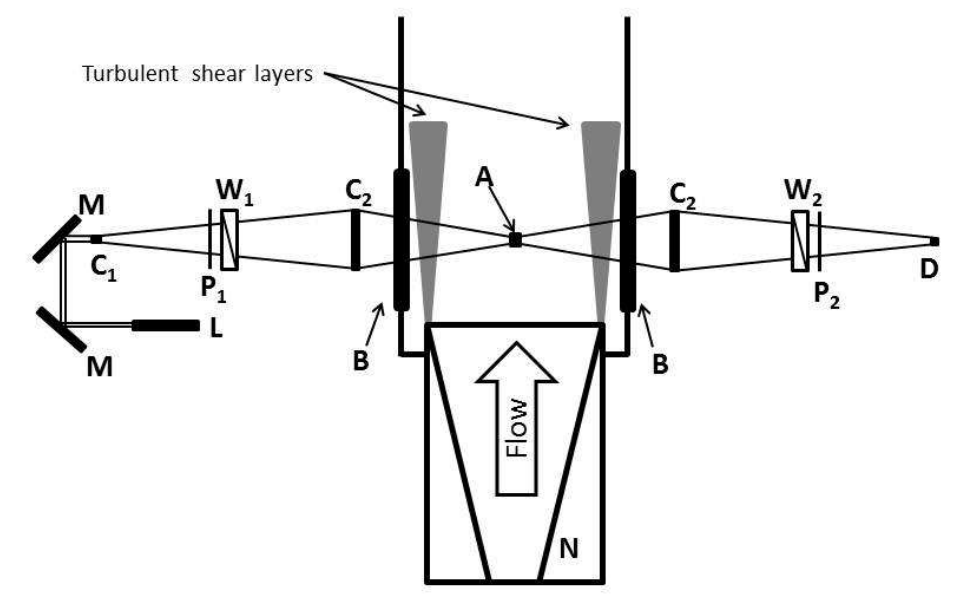

Figure 2. Annotated schematic of the FLDI. L, Laser; M, mirror; C, lens; P, polarizer; W, Wollaston prism; B, window; A, probe volume; D, photodetector; N, nozzle.

The laser used in this experiment is a Spectra-Physics Excelsior diode pumped solid state continuous wave laser (532 nm wavelength, $200 \mathrm{~mW}$ power). A beam splitter was used to make two FLDI's that are nearly identical to the single leg version that was first successfully used in T5 by Parziale et al. ${ }^{19,20}$ The high quality beam $\left(\mathrm{TEM}_{00}\right)$ does not require additional beam conditioning for use as an interferometer. Following the optical path in Fig. 2, starting from the laser, the beam is turned by a periscope arrangement for precise directional control. The beam is expanded by a lens, $\mathrm{C}_{1}$, and linearly polarized by $\mathrm{P}_{1}$ at $45^{\circ}$ to the plane of separation of the first Wollaston prism, $\mathrm{W}_{1}$. The plane of separation of $\mathrm{W}_{1}$ is chosen to be parallel to streamlines in the boundary layer of the five degree half angle cone. The prism splits the light by a narrow angle (2 arc minutes) into orthogonally polarized beams. The separation of the beams is fixed at $350 \mu \mathrm{m}$ by a lens, $\mathrm{C}_{2}$, while the diameter of the beams is reduced to small values in the center of the test section. This arrangement creates two beams with orthogonal polarization that share much of the same optical path. The orthogonally polarized beams do not share the same optical path within $\pm 10 \mathrm{~mm}$ of the focal point (along the beam direction, centered at A in Fig. 2). In this region the beams are calculated to be less than $100 \mu \mathrm{m}$ in diameter, and traverse separate but very closely spaced volumes; they are $350 \mu \mathrm{m}$ apart (assuming $1 / e^{2}$ Gaussian beam propagation ${ }^{35}$ ). It is primarily within this small focal region that the diagnostic is sensitive to changes in optical path length (OPL). The spatial resolution of the technique $(700 \mu \mathrm{m})$ is set by doubling the beam spacing to satisfy the Nyquist sampling theorem. Beyond the beam focus, the optical paths are again common and an additional lens, $\mathrm{C}_{2}$, re-focuses the beams. The Wollaston prism, $\mathrm{W}_{2}$, and polarizer, $\mathrm{P}_{2}$, recombine and then mix the orthogonally polarized beams, such that the interference will be registered as irradiance fluctuations by the photodetector. The response of the photodetector $(22.5 \mathrm{~V}$ battery biased FDS100 photodiode) is amplified (SRS SR445) at a gain of 25 and digitized at $100 \mathrm{MHz}$ by a 14-bit Ethernet oscilloscope (Cleverscope CS328A-XSE).

Two-beam differential interferometric methods are sensitive to differences in optical path length which are registered at a photodetector as changes in irradiance. The differences in optical path length are related to the gas density by the Gladstone-Dale relationship. The difference in density can then be expressed as, 


$$
\Delta \rho / \rho_{L}=\frac{\lambda_{0}}{2 \pi K L \rho_{L}} \sin ^{-1}\left(\frac{V}{V_{0}}-1\right),
$$

where, $\Delta \rho$ is the difference in density between the two beams, $\rho_{L}$ is the mean local density, $\lambda_{0}$ is the wavelength of the laser, $K$ is the Gladstone-Dale constant, $L$ is the integration length, $V$ is the potential registered by the photodetector during the experiments, and $V_{0}$ is the potential registered by the photodetector at the midpoint of a fringe. Each FLDI is set to the midpoint of a nearly infinite fringe before each experiment. The fringe shift during all experiments is less than $\pi / 3$, so there is no fringe ambiguity. More details concerning the measurement technique are given in previous reports. ${ }^{19,20}$

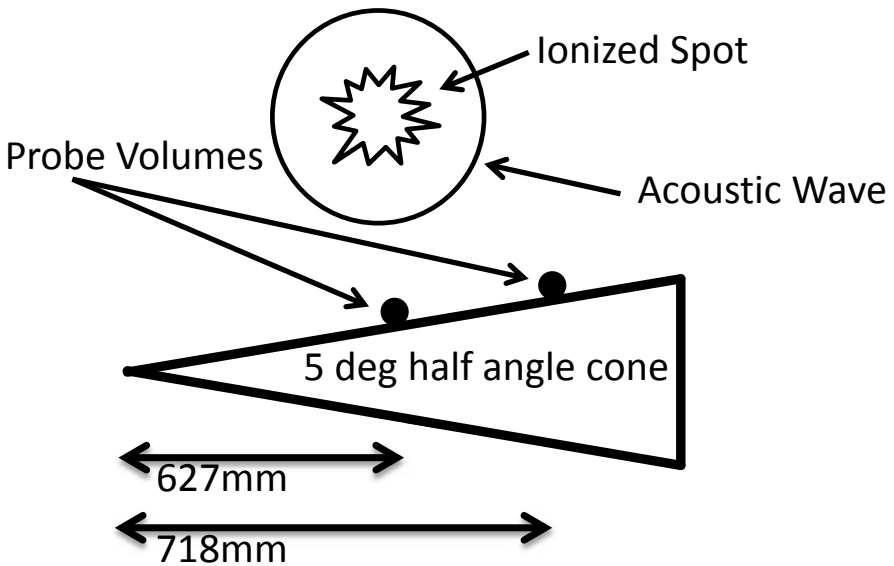

(a)

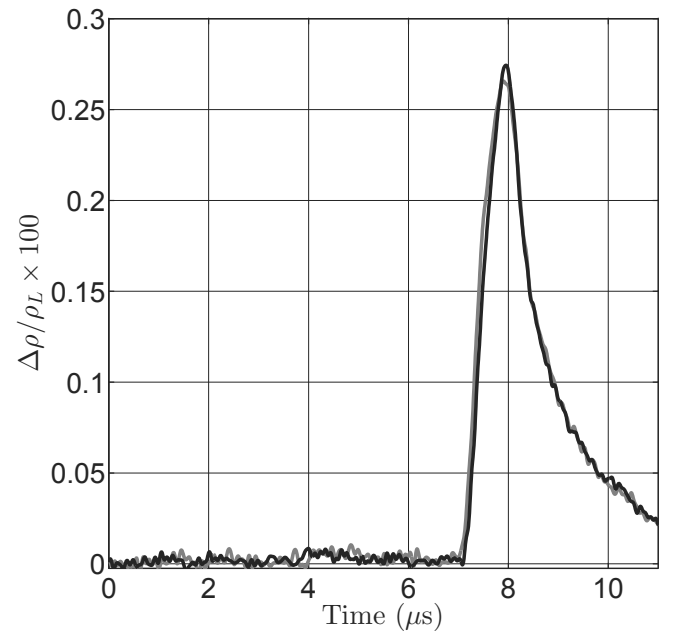

(b)

Figure 3. Above left (a), is a sketch of the bench test arrangement. The upstream and downstream probe volumes are denoted by circles. The ionized spot of gas is located equidistant from both detectors so that it creates a disturbance that is nearly identical at both probe volumes'. Above right (b), are the results of the bench test; the results show that the upstream and downstream interferometers respond similarly to a nearly identical disturbance.

Two FLDIs aligned along one generator of the cone are used in this work. The upstream probe volume is located $627 \pm 1 \mathrm{~mm}$ from the cone tip, the downstream probe volume is located $718 \pm 1 \mathrm{~mm}$ from the cone tip. Following the construction of the interferometers, a bench test was devised to determine if the sensitivity of the probe volumes is a strong function of the optical layout, i.e., is the response the same if an identical disturbance is imposed on each detector? To make the disturbance, a pulsed Nd:YAG laser (New Wave Research Gemini-200, $200 \mathrm{~mJ}, 5 \mathrm{~ns}$ pulse), is focused to a point by a $200 \mathrm{~mm}$ lens to ionize a spot of gas. This ionized spot of gas acts as a spherical piston and creates a weak blast wave. If the time of arrival of the disturbance at each of the probe volumes is nearly identical, and it is assumed that the weak blast wave is symmetric, the disturbance amplitude at each of the probe volumes can be assumed to be nearly identical (schematic in Fig. 3(a)). The result of a such a test (Fig. 3(b)) indicates that the upstream and downstream FLDI signals are nearly identical, they differ in peak response by less than $4.0 \%$. The experiment is conducted five times and the difference in response is found to be repeatable; the upstream detector's response is found to be $3.5 \% \pm 0.5 \%$ higher than in the downstream detector.

\section{Air Series}

Air is used as the test gas in the series of experiments presented in this section. The reservoir pressure is held approximately constant, while the reservoir enthalpy is varied (Table 1). The edge unit Reynolds number decreases when the reservoir pressure is held constant and the reservoir enthalpy is increased. The purpose of this campaign is to measure the incipient instability waves prior to the transition to fully turbulent flow. The ultimate goal is to determine the role of the acoustic instability on the transition process. The FLDI measurement volumes are located just upstream of the transition location to measure the instability waves. Boundary layer transition is identified by departure from laminar surface heat-flux rates measured by surface mounted heat-transfer gauges. ${ }^{36,37}$ 
Table 1. Summary of edge conditions for the air shot series in this section.

\begin{tabular}{cccccccccc} 
Shot & $\begin{array}{c}h_{R} \\
(\mathrm{MJ} / \mathrm{kg})\end{array}$ & $\begin{array}{c}P_{R} \\
(\mathrm{MPa})\end{array}$ & $\begin{array}{c}U_{E} \\
(\mathrm{~m} / \mathrm{s})\end{array}$ & $\begin{array}{c}P_{E} \\
(\mathrm{kPa})\end{array}$ & $\begin{array}{c}T_{E} \\
(\mathrm{~K})\end{array}$ & $\begin{array}{c}T v_{E} \\
(\mathrm{~K})\end{array}$ & $\begin{array}{c}\rho_{E} \\
\left(\mathrm{~kg} / \mathrm{m}^{3}\right)\end{array}$ & $\begin{array}{c}M_{E} \\
(-)\end{array}$ & $\begin{array}{c}R e_{E}^{\text {Unit }} \\
(1 / \mathrm{m})\end{array}$ \\
\hline 2767 & 9.02 & 16.6 & 3750 & 10.0 & 780 & 690 & 0.024 & 4.86 & $1.67 \mathrm{E}+06$ \\
2766 & 7.55 & 17.0 & 3480 & 9.81 & 990 & 860 & 0.028 & 4.99 & $2.07 \mathrm{E}+06$ \\
2765 & 6.48 & 17.5 & 3270 & 9.61 & 1190 & 1040 & 0.033 & 5.15 & $2.56 \mathrm{E}+06$ \\
2764 & 5.28 & 16.5 & 2980 & 8.26 & 1430 & 1260 & 0.037 & 5.32 & $2.99 \mathrm{E}+06$
\end{tabular}

For this shot series, the two FLDI probe volumes at $627 \pm 1 \mathrm{~mm}$ and $718 \pm 1 \mathrm{~mm}$ are positioned $910 \pm 50 \mu \mathrm{m}$ and $970 \pm 50 \mu \mathrm{m}$ from the surface of the cone, respectively. The difference in wall-normal distance is intended to account for the boundary layer growth between the stations; the locations were chosen to probe near a maximum of the eigenfunction of density to attain the highest and most consistent signal to noise ratio.

Band-pass filtered time traces of the non-dimensional fluctuations in density $\left(\Delta \rho / \rho_{L}\right)$ at two points in the boundary layer show an increase in RMS response as the edge unit Reynolds number is increased (top of each plot in Fig. 4). Cross-correlation is used to estimate the extent to which the response at the upstream detector is related to the response at the downstream detector in a time-lag sense (bottom of each plot in Fig. 4). The ordinates in the cross-correlation plots are normalized by the square root of the product of the auto-covariences at zero lag, so that the maximum correlation would be unity if at any lag the signal upstream is identical to the signal downstream. A peak in cross-correlation at a time-lag, $\tau$, is nearly consistent with the time scale associated with the edge velocity and the detector spatial separation, $\Delta s$ (Table 2). These peaks in cross-correlation appear when both the upstream and downstream band-pass filtered time-traces of $\Delta \rho / \rho_{L}$ show low-amplitude, wave packet like behavior. This implies that the detectors are tracking wave packets that are traveling along the generator of the cone at approximately the edge velocity.

To further classify the signals, estimates of the power spectral density for each case are computed using Welch's method, with 50\% overlapping $20 \mu$ s Hann windows (Fig. 5). As the Reynolds number is increased, a narrow-band spectral peak increases in amplitude until some value, and then broadens out. This behavior is consistent with a fluid-dynamic instability increasing in amplitude and then breaking down to turbulence. This assertion is supported by a corresponding departure from laminar surface heat-flux rates measured by surface mounted heat-transfer gauges (not shown). ${ }^{36,37}$ Note that there is a peak in the cross-correlation only when both detectors have a distinct narrow-band spectral response. The peak in the cross-correlation indicates that there are discrete packets of narrow-band disturbance that are traceable from the upstream detector to the downstream detector.

Table 2. Boundary layer scaling for the air shot series (conditions summarized in Table 1).

\begin{tabular}{cccccccccc} 
Shot & $\begin{array}{c}U_{E} \\
(\mathrm{~m} / \mathrm{s})\end{array}$ & $\begin{array}{c}\tau \\
(\mu \mathrm{s})\end{array}$ & $\begin{array}{c}\tau / \Delta s \\
(\mathrm{~m} / \mathrm{s})\end{array}$ & $\begin{array}{c}\delta_{U} \\
(\mu \mathrm{m})\end{array}$ & $\begin{array}{c}f_{U} \\
(\mathrm{kHz})\end{array}$ & $\begin{array}{c}2 f_{U} \delta_{U} / U_{E} \\
(-)\end{array}$ & $\begin{array}{c}\delta_{D} \\
(\mu \mathrm{m})\end{array}$ & $\begin{array}{c}f_{D} \\
(\mathrm{kHz})\end{array}$ & $\begin{array}{c}2 f_{D} \delta_{D} / U_{E} \\
(-)\end{array}$ \\
\hline 2767 & 3750 & 24.5 & 3720 & 2090 & 615 & 0.69 & 2240 & 580 & 0.69 \\
2766 & 3480 & 26.4 & 3440 & 1930 & 617 & 0.68 & 2060 & 577 & 0.68 \\
2765 & 3270 & - & - & 1800 & 571 & 0.63 & 1920 & - & - \\
2764 & 2980 & - & - & 1720 & - & - & 1840 & - & -
\end{tabular}

The narrow-band peaks observed in the spectral estimates are consistent with the acoustic mode first described by Mack. ${ }^{38}$ An estimate of the most strongly amplified frequency $f \approx K U_{E} /(2 \delta) .{ }^{12,39}$ The frequency of the spectral peak at the upstream detector, $f_{U}$, is higher than the frequency of the spectral peak at the downstream detector, $f_{D}$; as expected, the frequency is inversely proportional to the computed boundary layer thickness (Table 2). This behavior is consistent with the hypothesis that as the effective waveguide grows in size, the frequency should decrease correspondingly.

High-speed schlieren cinematography from a conventional z-type setup ${ }^{40}$ also appears to capture the instability (Fig. 6). The 192x56 pixel images are recorded at 320k frames per second with a Vision Research Phantom v710. The light source is a high-power laser diode (905 nm, PN: 905D3S3J09R), pulsed for $12 \mathrm{~ns}$ by a LDP-V 50-100 V3 driver module from Laser Components. The center of the field of view is downstream of both FLDI detectors, approximately $780 \mathrm{~mm}$ from the tip of the cone. Ten frames are selected that bracket a frame in time when an interesting disturbance is observed in post-processing. An average is constructed, 

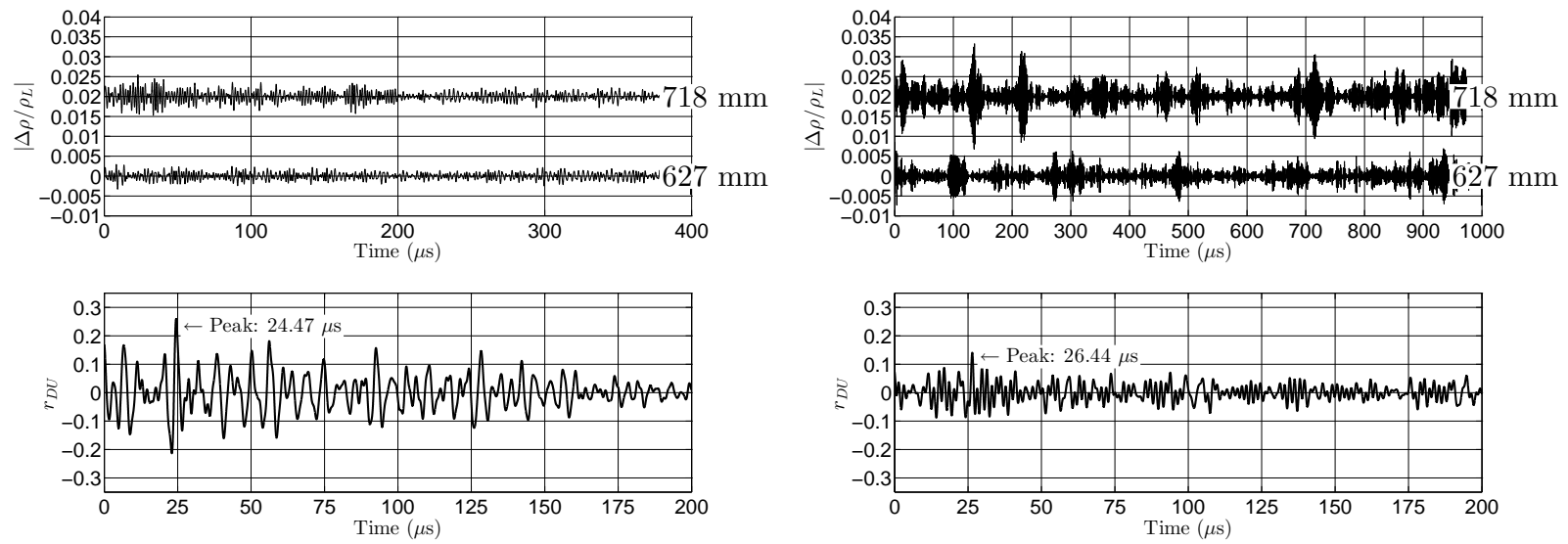

(a) Shot 2767: $R e_{E}^{U n i t}=1.67 \mathrm{E} 6(1 / \mathrm{m})$
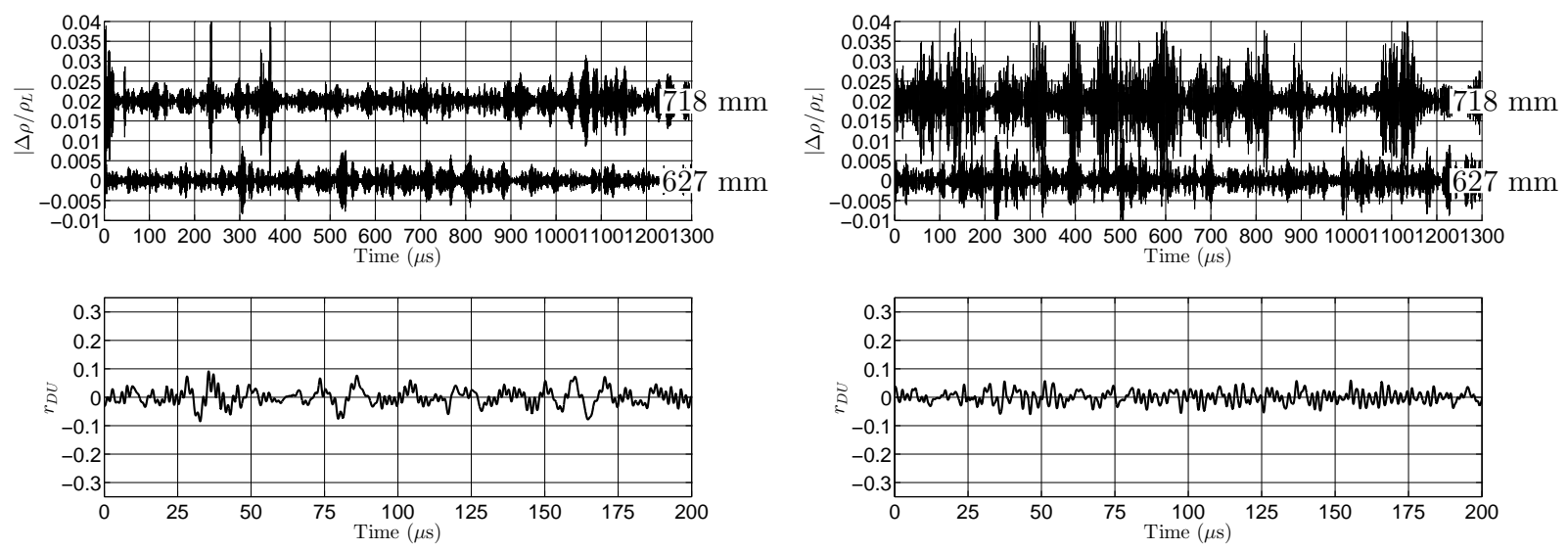

(c) Shot 2765: $R e_{E}^{U \text { nit }}=2.56 \mathrm{E} 6(1 / \mathrm{m})$

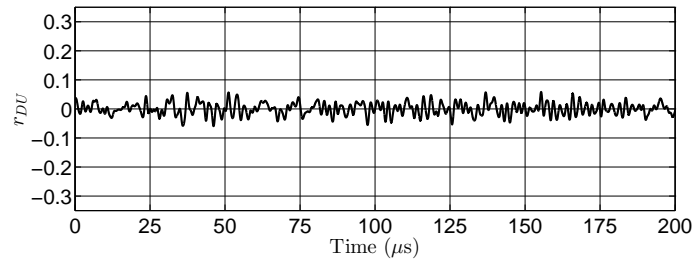

(d) Shot 2764: $\operatorname{Re}_{E}^{U \text { Unit }}=2.99 \mathrm{E} 6(1 / \mathrm{m})$

Figure 4. Time traces and cross-correlations of $\Delta \rho / \rho_{L}$ for the air shot series (conditions summarized in Table 1).

and 75 percent of the average is subtracted from each frame for contrast enhancement. The image shows the structures of the instability to be inclined at a 13-26 deg angle to the surface. It is noted to be similar to the results presented in VanDercreek ${ }^{41}$ and Laurence et al. ${ }^{42}$ 


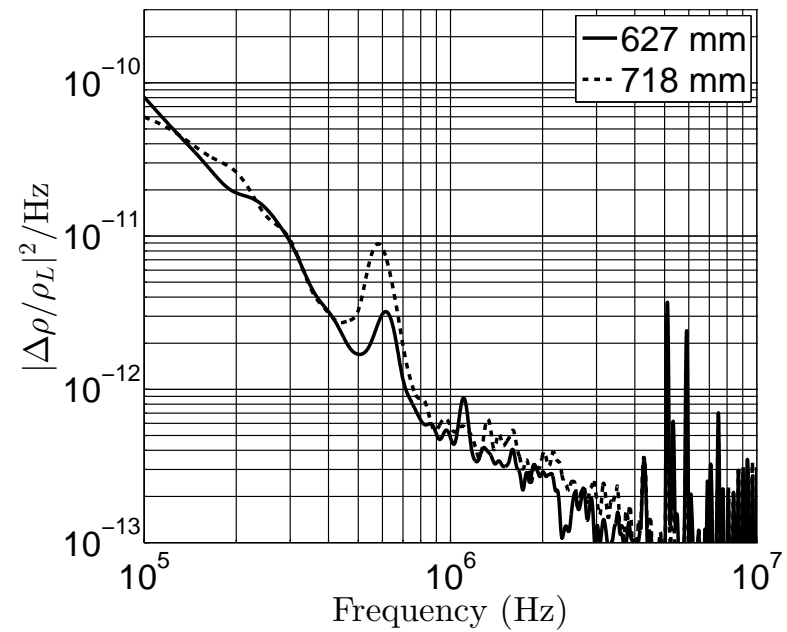

(a) Shot 2767: $\operatorname{Re}_{E}^{U \text { nit }}=1.67 \mathrm{E} 6(1 / \mathrm{m})$

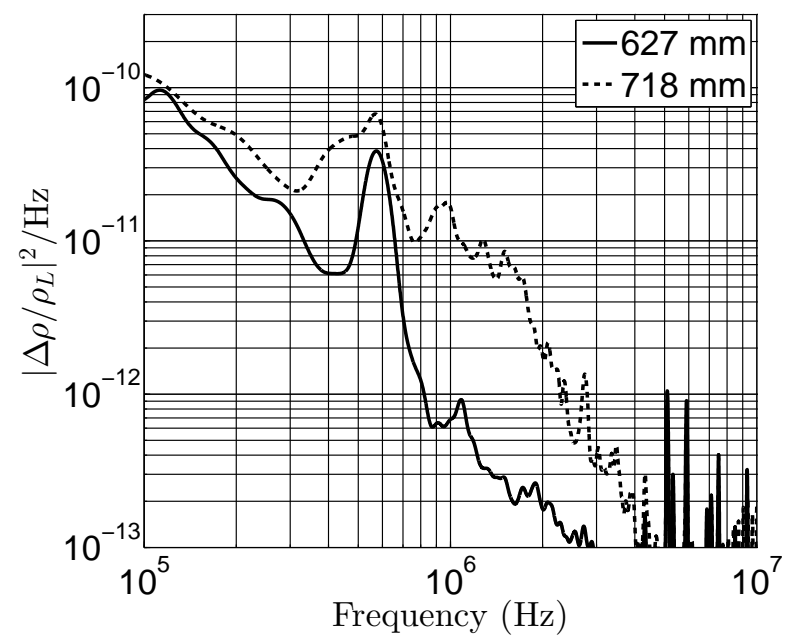

(c) Shot 2765: $R e_{E}^{U n i t}=2.56 \mathrm{E} 6(1 / \mathrm{m})$

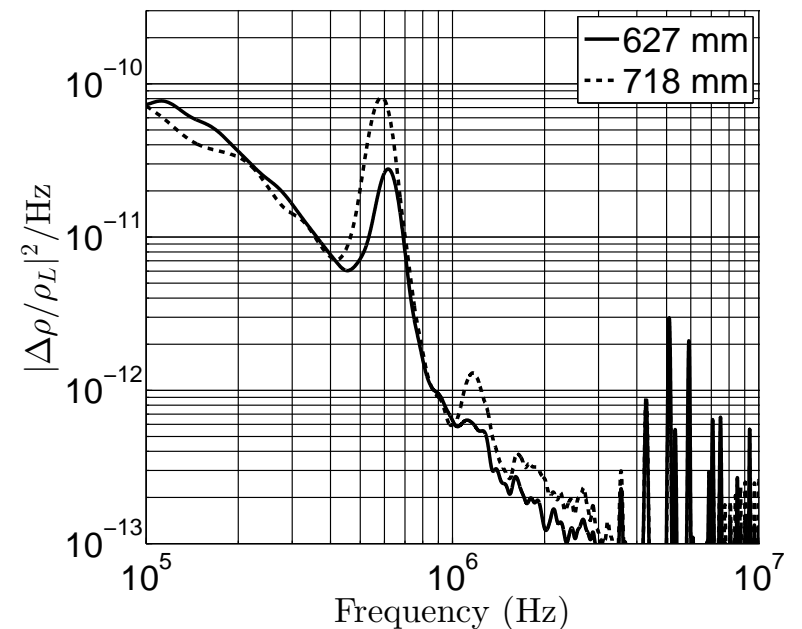

(b) Shot 2766: $R e_{E}^{U n i t}=2.07 \mathrm{E} 6(1 / \mathrm{m})$

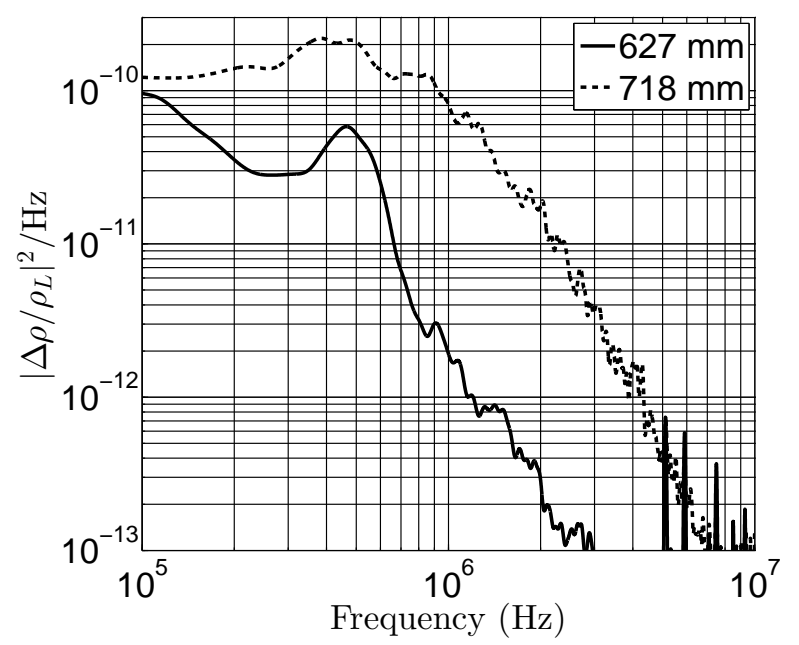

(d) Shot 2764: $R e_{E}^{U n i t}=2.99 \mathrm{E} 6(1 / \mathrm{m})$

Figure 5. Power spectral density estimates of $\Delta \rho / \rho_{L}$ for the air shot series (conditions summarized in Table 1).
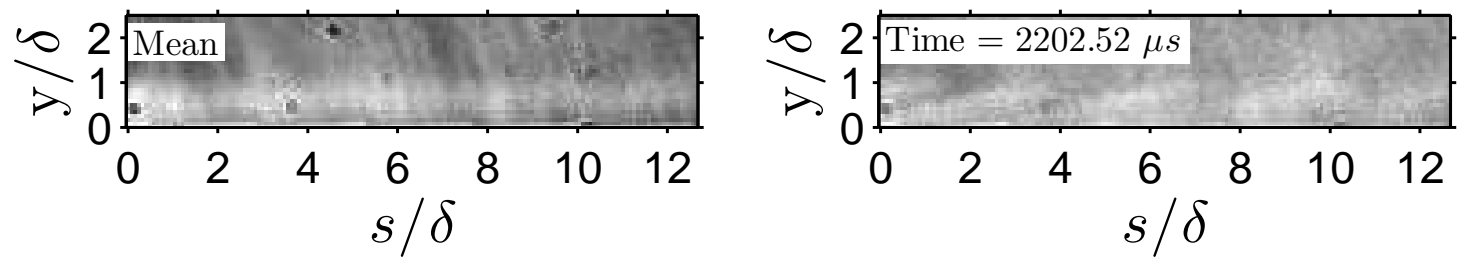

Figure 6. Schlieren images from shot 2766. On the left is the mean of ten frames, on the right is a snapshot of the instability. The time stamp indicates the delay from the pressure rise in the reservoir. The flow is from left to right. The calculated boundary layer thickness (Table 2) and a length scale (allen key) placed in the image plane prior to the experiment are used to formulate the axes labels.

\section{V. $\mathbf{N}_{2}$ Series}

Nitrogen is used as the test gas in the series of experiments presented in this section. The reservoir pressure is held approximately constant, while the reservoir enthalpy is varied (Table 3). The purpose of this campaign is to repeat the tests discussed in Section IV at as similar conditions as experimentally possible, but with a different test gas. This allows for the identification of any first order effects that would significantly differentiate air and $\mathrm{N}_{2}$ as a test gas at these conditions. Again, the edge unit Reynolds number decreases 
when the reservoir pressure is held constant and the reservoir enthalpy is increased. For this shot series, the two FLDI probe volumes at $627 \pm 1 \mathrm{~mm}$ and $718 \pm 1 \mathrm{~mm}$ are positioned $940 \pm 50 \mu \mathrm{m}$ and $990 \pm 50 \mu \mathrm{m}$ from the surface of the cone, respectively. The probe volumes are located at a different wall-normal surface location to account for the change in boundary layer thickness, which scales as, $\delta / s \propto M_{E}^{2} / \sqrt{R e_{s E}}$, ${ }^{43}$ where $s$ is the distance along the cone surface, and $R e_{s E}$ is the edge Reynolds number based on distance from the cone tip.

The results for the nitrogen test series are qualitatively similar to those for air. An increase in RMS response of $\Delta \rho / \rho_{L}$ as the edge unit Reynolds number is increased can be observed (top of each plot in Fig. 7). A peak in cross-correlation at a time-lag, $\tau$, is nearly consistent with the time scale associated with the edge velocity and the detector spatial separation, $\Delta s$ (Table 4 ). These peaks in cross-correlation appear when both the upstream and downstream band-pass filtered time-traces of $\Delta \rho / \rho_{L}$ show low-amplitude, wave packet like behavior (Fig. 7). This implies that the detectors are tracking wave packets that are traveling along the generator of the cone at approximately the edge velocity. This is similar in behavior as the air series presented in in Section IV.

Table 3. Summary of edge conditions for the $\mathrm{N}_{2}$ Series.

\begin{tabular}{cccccccccc} 
Shot & $\begin{array}{c}h_{R} \\
(\mathrm{MJ} / \mathrm{kg})\end{array}$ & $\begin{array}{c}P_{R} \\
(\mathrm{MPa})\end{array}$ & $\begin{array}{c}U_{E} \\
(\mathrm{~m} / \mathrm{s})\end{array}$ & $\begin{array}{c}P_{E} \\
(\mathrm{kPa})\end{array}$ & $\begin{array}{c}T_{E} \\
(\mathrm{~K})\end{array}$ & $\begin{array}{c}T v_{E} \\
(\mathrm{~K})\end{array}$ & $\begin{array}{c}\rho_{E} \\
\left(\mathrm{~kg} / \mathrm{m}^{3}\right)\end{array}$ & $\begin{array}{c}M_{E} \\
(-)\end{array}$ & $\begin{array}{c}\text { Re } e_{E}^{\text {Unit }} \\
(1 / \mathrm{m})\end{array}$ \\
\hline 2774 & 10.1 & 16.7 & 4050 & 7.03 & 1180 & 3309 & 0.020 & 5.76 & $1.74 \mathrm{E}+06$ \\
2773 & 8.99 & 16.7 & 3850 & 6.85 & 1045 & 3141 & 0.022 & 5.83 & $1.97 \mathrm{E}+06$ \\
2772 & 7.99 & 16.7 & 3650 & 6.78 & 925 & 3018 & 0.025 & 5.88 & $2.25 \mathrm{E}+06$ \\
2775 & 7.23 & 17.4 & 3490 & 7.13 & 846 & 2927 & 0.028 & 5.88 & $2.61 \mathrm{E}+06$
\end{tabular}
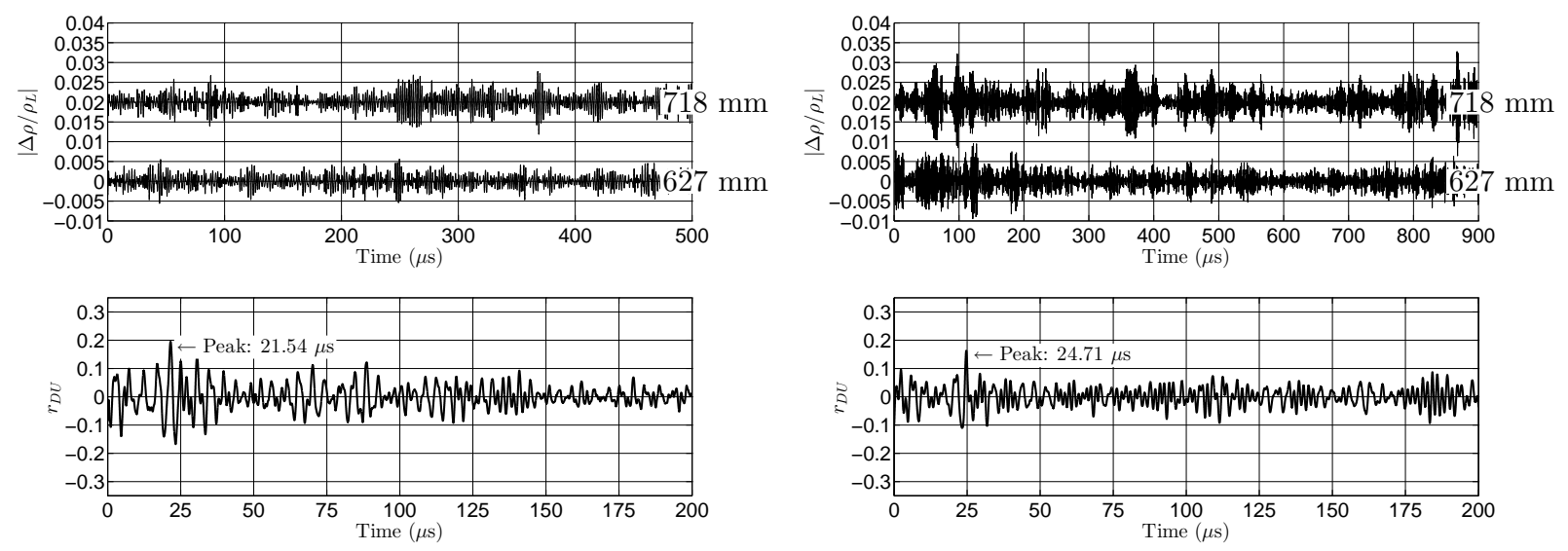

(a) Shot 2774: $R e_{E}^{U n i t}=1.74 \mathrm{E} 6(1 / \mathrm{m})$
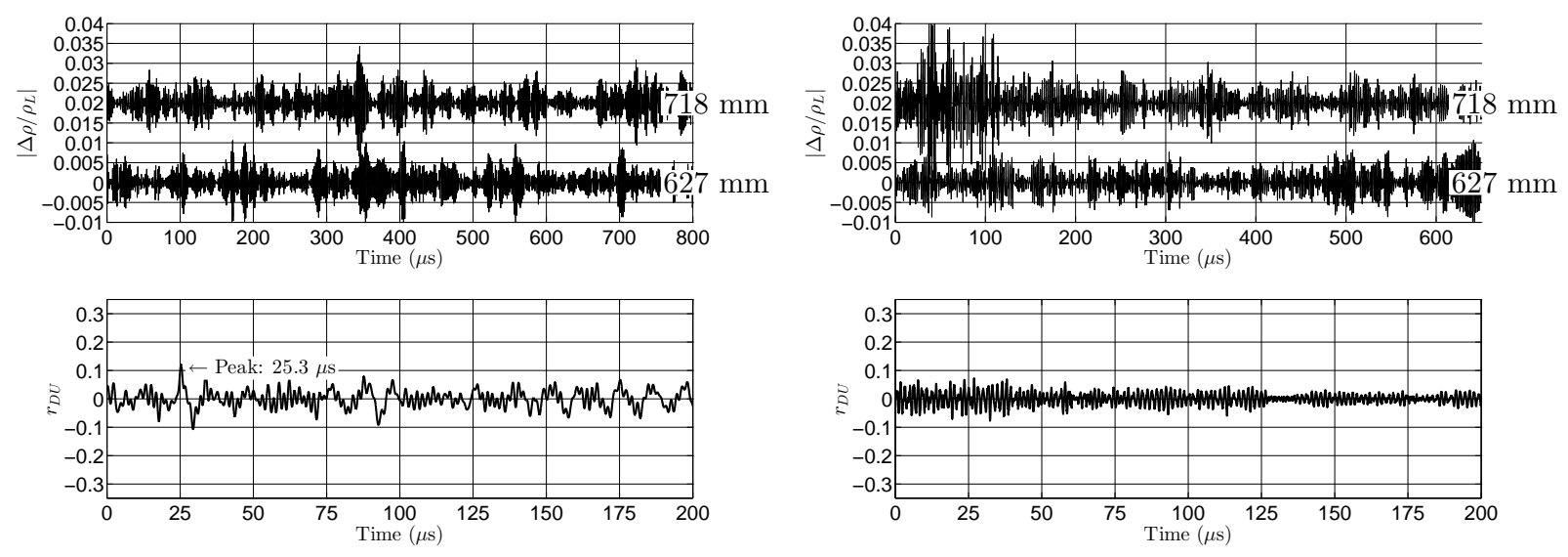

(c) Shot 2772: $R e_{E}^{U n i t}=2.25 \mathrm{E} 6(1 / \mathrm{m})$

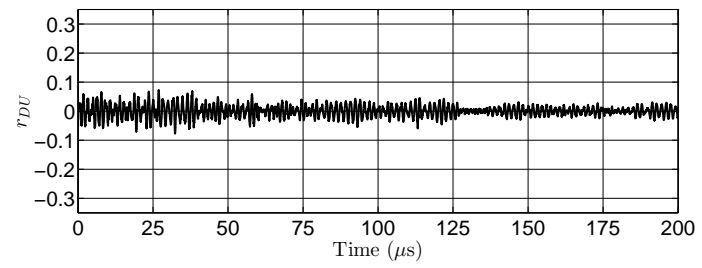

(d) Shot 2775: $R e_{E}^{U n i t}=2.61 \mathrm{E} 6(1 / \mathrm{m})$

Figure 7. Time traces and cross-correlations of $\Delta \rho / \rho_{L}$ for the $\mathbf{N}_{2}$ shot series (conditions summarized in Table 3). 
Welch's method, with $50 \%$ overlapping $20 \mu \mathrm{s}$ Hann, windows, is used to make estimates of the power spectral density for each case (Fig. 8). As the Reynolds number is increased, a narrow-band spectral peak increases in amplitude until it saturates, and then broadens out, similar in behavior as the air series presented in in Section IV.

The narrow-band peaks observed in the spectral estimates are again consistent with the acoustic mode. The frequency of the spectral peak at the upstream detector, $f_{U}$, is higher than the frequency of the spectral peak at the downstream detector, $f_{D}$; the frequency is inversely proportional to the computed boundary layer thickness (Table 4).
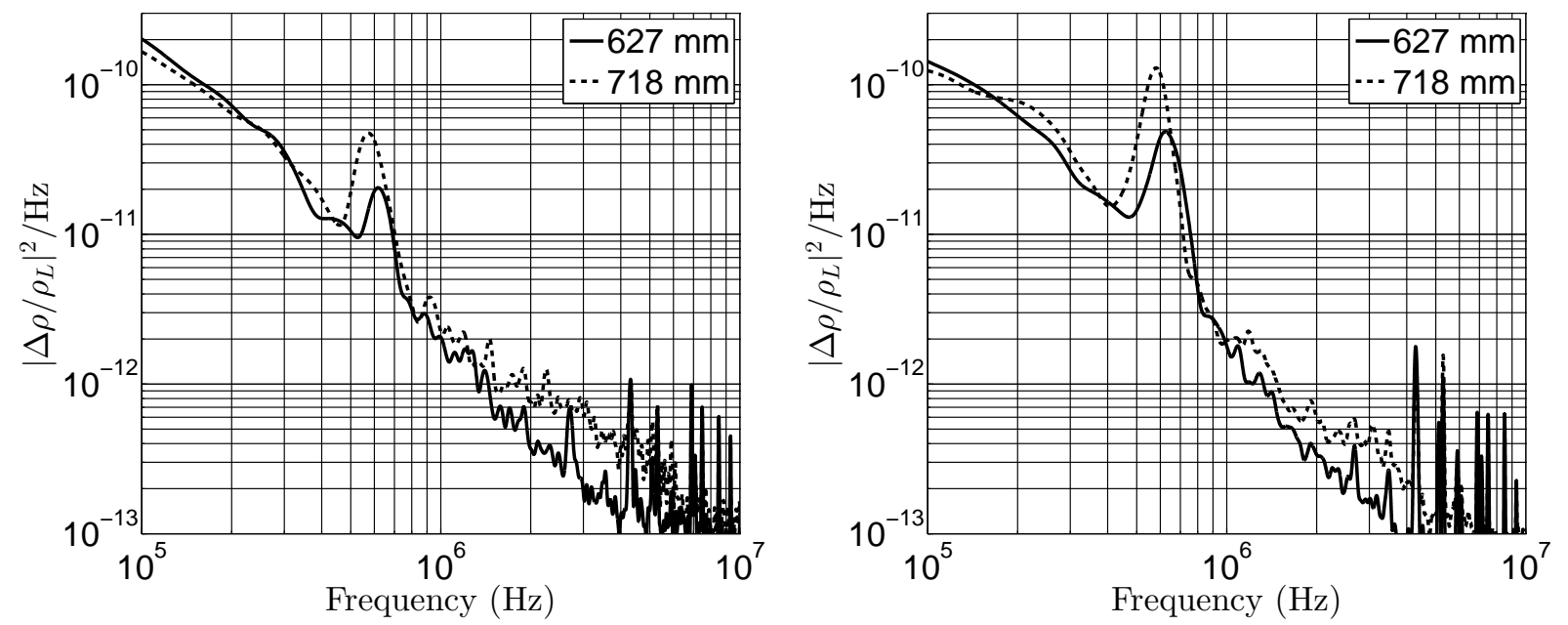

(a) Shot 2774: $R e_{E}^{U n i t}=1.74 \mathrm{E} 6(1 / \mathrm{m})$
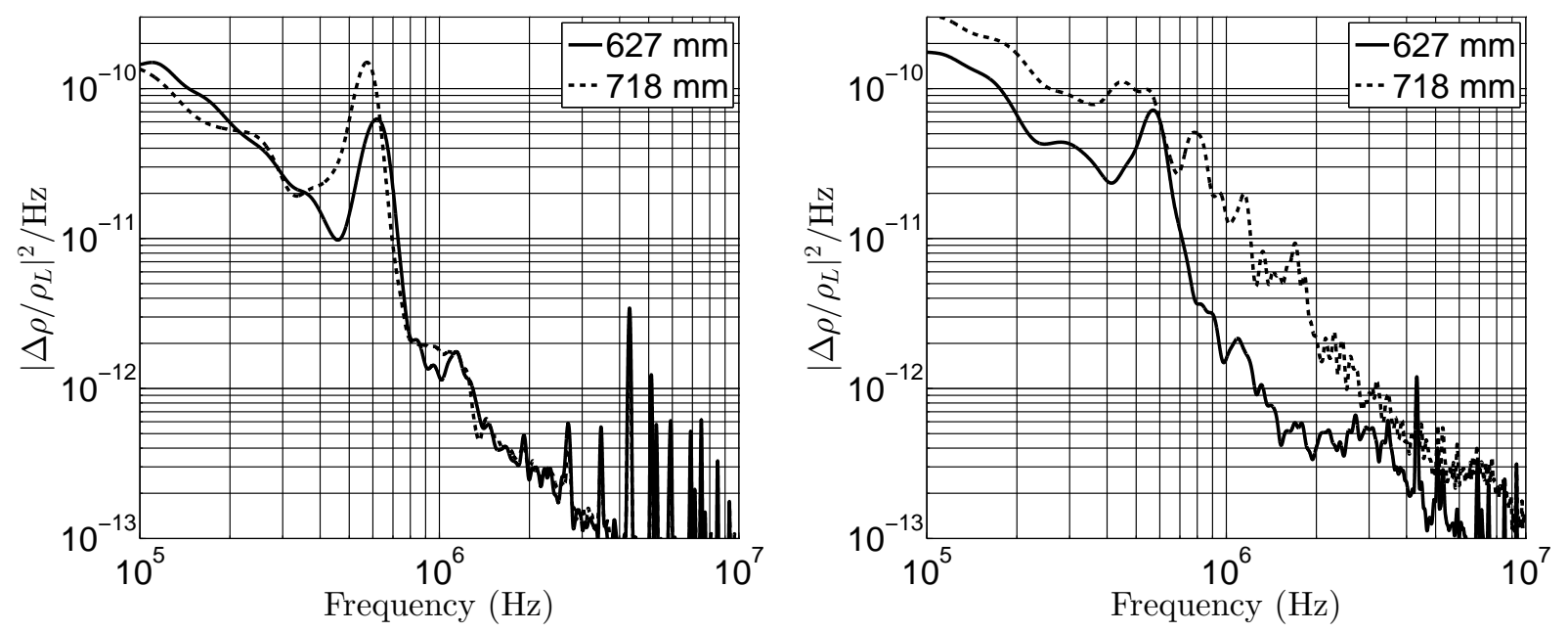

(c) Shot 2772: $\operatorname{Re}_{E}^{U n i t}=2.25 \mathrm{E} 6(1 / \mathrm{m})$

(d) Shot 2775: $R e_{E}^{U n i t}=2.61 \mathrm{E} 6(1 / \mathrm{m})$

Figure 8. Power spectral density estimates of $\Delta \rho / \rho_{L}$ for the $\mathbf{N}_{2}$ shot series (conditions summarized in Table 3).

High-speed schlieren cinematography from a conventional z-type setup ${ }^{40}$ also appears to capture the instability (Fig. 9). The 256x128 pixel images are recorded at 150k frames per second with a Vision Research Phantom v710. The light source is a high-power laser diode (905 nm, PN: 905D3S3J09R), pulsed for $12 \mathrm{~ns}$ by a LDP-V 50-100 V3 driver module from Laser Components. The center of the field of view is downstream of both FLDI detectors, approximately $780 \mathrm{~mm}$ from the tip of the cone. Ten frames that bracket a frame in time when an interesting disturbance is observed in post-processing are selected. An average is constructed, and 75 percent of the average is subtracted from each frame for contrast enhancement. The image shows the structures of the instability to be inclined at a 13-26 deg angle to the surface. It is noted to be similar to the results presented in VanDercreek ${ }^{41}$ and Laurence et al. ${ }^{42}$ The appearance of the structures is similar to those in air (Fig. 9). 
Table 4. Boundary layer scaling the $\mathrm{N}_{2}$ shot series (conditions summarized in Table 3).

\begin{tabular}{|c|c|c|c|c|c|c|c|c|c|}
\hline Shot & $\begin{array}{c}U_{E} \\
(\mathrm{~m} / \mathrm{s})\end{array}$ & $\begin{array}{c}\tau \\
(\mu \mathrm{s})\end{array}$ & $\begin{array}{l}\tau / \Delta s \\
(\mathrm{~m} / \mathrm{s})\end{array}$ & $\begin{array}{c}\delta_{U} \\
(\mu \mathrm{m})\end{array}$ & $\begin{array}{c}f_{U} \\
(\mathrm{kHz})\end{array}$ & $\begin{array}{c}2 f_{U} \delta_{U} / U_{E} \\
(-)\end{array}$ & $\begin{array}{c}\delta_{D} \\
(\mu \mathrm{m})\end{array}$ & $\begin{array}{c}f_{D} \\
(\mathrm{kHz})\end{array}$ & $\begin{array}{c}2 f_{D} \delta_{D} / U_{E} \\
(-)\end{array}$ \\
\hline 2774 & 4050 & 21.5 & 4230 & 2360 & 597 & 0.70 & 2530 & 559 & 0.70 \\
\hline 2773 & 3850 & 24.7 & 3680 & 2240 & 620 & 0.72 & 2400 & 581 & 0.72 \\
\hline 2772 & 3650 & 25.3 & 3600 & 2120 & 620 & 0.72 & 2280 & 571 & 0.71 \\
\hline 2775 & 3490 & - & - & 1970 & 610 & 0.69 & 2120 & - & - \\
\hline & & & & & & w $3 \sqrt{\mathrm{Tin}}$ & $=13$ & 84 & \\
\hline 0 & 2 & 6 & $\begin{array}{l}810 \\
/ \delta\end{array}$ & 121 & & 0 & 4 & $\begin{array}{l}68 \\
s / \delta\end{array}$ & 101214 \\
\hline
\end{tabular}

Figure 9. Schlieren images from shot 2773. On the left is the mean of ten frames, on the right is a snapshot of the instability. The time stamp indicates the delay from the pressure rise in the reservoir. The flow is from left to right. The calculated boundary layer thickness (Table 4) and a length scale (allen key) placed in the image plane prior to the experiment are used to formulate the axes labels.

\section{Preliminary Comparison of Air and $\mathrm{N}_{2}$ shots}

A comparison of four experiments discussed in Sections IV and V is presented. The four shots are chosen to have the following behavior: 1) there is no significant departure from computed laminar heating rates, 2) there is a peak in the cross-correlations that indicates the existence of discrete packets, and 3) there is no obvious spectral behavior that would indicate the wave packets are non-linear or turbulent. To make a preliminary estimate of the experimentally measured change in amplitude between stations we choose an amplification factor, $N$ as,

$$
N=\ln \left(\left|A_{D}\right| /\left|A_{U}\right|\right)=\ln \left(\left|\Delta \rho_{D}\right| /\left|\Delta \rho_{U}\right|\right)=\frac{1}{2} \ln \left(\frac{\left|\Delta \rho_{D} / \rho_{L}\right|^{2} / H z}{\left|\Delta \rho_{U} / \rho_{L}\right|^{2} / H z}\right)
$$

where the chosen disturbance amplitude ratio, $A_{D} / A_{U}$, is the density fluctuation ratio, $\left|\Delta \rho_{D}\right| /\left|\Delta \rho_{U}\right|$.

Power spectral density estimates (PSD's) in Figs. 5(a), 5(b), 8(a), and 8(b) are used with Eq. 2 to compute experimental amplification factors (Fig. 10). The PSD's are only used where there appears to have sufficient signal to noise ratio. ${ }^{\mathrm{a}}$. The maximum amplification factor was observed to be $N \approx 0.5-0.9$ for the detector spacing $\Delta s=91 \mathrm{~mm}$. This is similar to the order of magnitude of maximum growth rates computed by linear stability theory. ${ }^{44}$ Error bars are placed at the maximum $N$ factor, representing $35 \%$ systematic error. This estimate is obtained by combining the calculation of errors in Parziale et al., ${ }^{20}$ wall-normal distance misalignment, and difference in relative response (discussed in Section III) in an RMS sense. ${ }^{45,46}$ Misalignment in wall-normal location from the maximum of the eigenfunction of density leads to error in density fluctuation amplitude ratios, $\left|\Delta \rho_{D}\right| /\left|\Delta \rho_{U}\right|$. This systematic error magnitude is estimated on the basis of relative boundary layer thickness to wall-normal probe point. There appears to be no statistically significant difference in computed amplification factor for any of the shots considered. To confirm this, a more rigorous estimate of systematic and random error must be made to reduce the presented error bars.

One explanation for a difference between amplification factor while testing $\mathrm{N}_{2}$ and air at similar conditions is that the $\mathrm{O}_{2}$ is more thermo-chemically active than $\mathrm{N}_{2}$. Acoustic waves propagating through a gas are attenuated by relaxation processes. It is postulated that significant damping of the acoustic instability will occur if the instability and thermo-chemical relaxation time scales are nearly matched. The code developed by Fujii ${ }^{6}$ and Fujii and Hornung ${ }^{47,48}$ is used to make a quantitative estimate of this damping. The absorption per wavelength at the boundary layer Eckert reference temperature ${ }^{49}$ for representative shots in $\mathrm{N}_{2}$ and air is shown in Fig. 11. Absorption is negligible for both gases at the frequencies associated with the measured acoustic disturbances (Fig. 10).

\footnotetext{
${ }^{\mathrm{a}} \mathrm{A}$ more in depth discussion of signal to noise ratio may be found in Parziale et al. ${ }^{20}$
} 


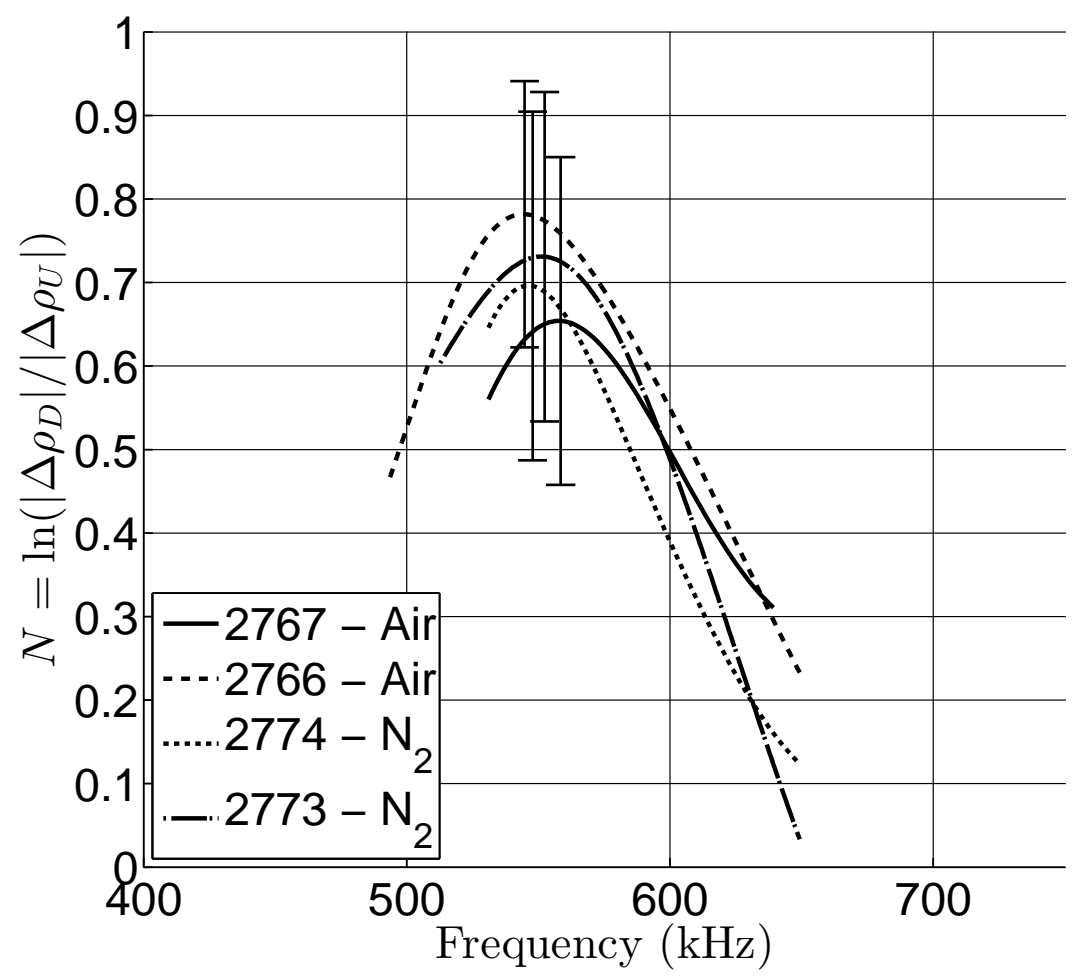

Figure 10. Experimentally computed amplification factor between the FLDI probe volumes at $627 \pm 1 \mathrm{~mm}$ and $718 \pm 1 \mathrm{~mm}$ from the cone tip, calculated by using Eq. 2 and the PSD's in Figs. 5(a), 5(b), 8(a), and 8(b).

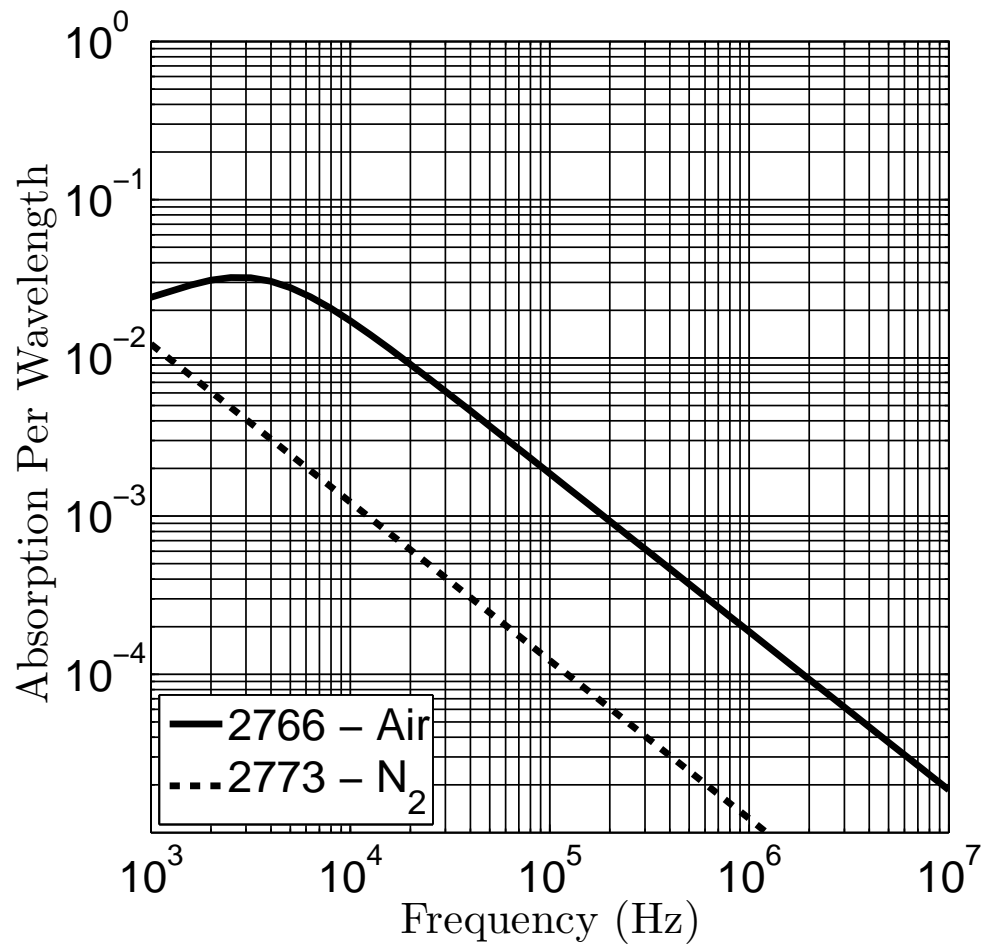

Figure 11. Curve for absorption per unit wavelength for shot 2766 (air) and shot 2773 (N ${ }_{2}$ ). Note that no appreciable absorption per wavelength should be observed in the frequency range relevant to the acoustic instability. 


\section{High Enthalpy Examples}

Two example cases at high reservoir enthalpy are presented in this section. Significantly higher edge velocities are calculated in both cases (Table 5). Preliminary analysis of the time traces and cross-correlations lead to similar results as described in Sections IV and V. There is a peak in the cross-correlation when the disturbances show low-amplitude wave packet like behavior at both detectors (Fig. 12). This indicates that in shot 2781, there are wave packets that are traveling along a generator of the cone at approximately the edge velocity.

Welch's method, with $50 \%$ overlapping $10 \mu$ s Hann windows, is used to make estimates of the power spectral density for each case (Fig. 13). Note that the frequency of disturbance is higher than in the previous two sections. The boundary layer is thinner because of changes in Reynolds number and edge Mach number $\left(\delta / s \propto M_{E}^{2} / \sqrt{R e_{s E}}\right) .{ }^{43} \quad \mathrm{~A}$ thinner boundary layer and a higher edge velocity result in a correspondingly higher frequency of disturbance (Table 6). To account for this change, the two FLDI probe volumes at $627 \pm 1 \mathrm{~mm}$ and $718 \pm 1 \mathrm{~mm}$ are positioned $460 \pm 50 \mu \mathrm{m}$ and $530 \pm 50 \mu \mathrm{m}$ from the surface of the cone, respectively.

Table 5. Summary of edge conditions for the high enthalpy shots.

\begin{tabular}{ccccccccccc} 
Shot & Gas & $h_{R}$ & $P_{R}$ & $U_{E}$ & $P_{E}$ & $T_{E}$ & $T v_{E}$ & $\rho_{E}$ & $M_{E}$ & $R e_{E}^{\text {Unit }}$ \\
\hline & & $(\mathrm{MJ} / \mathrm{kg})$ & $(\mathrm{MPa})$ & $(\mathrm{m} / \mathrm{s})$ & $(\mathrm{kPa})$ & $(\mathrm{K})$ & $(\mathrm{K})$ & $\left(\mathrm{kg} / \mathrm{m}^{3}\right)$ & $(-)$ & $(1 / \mathrm{m})$ \\
2769 & Air & 10.5 & 60.8 & 4060 & 39.2 & 1757 & 1699 & 0.077 & 4.79 & $5.18 \mathrm{E}+06$ \\
2781 & $\mathrm{~N}_{2}$ & 15.0 & 43.4 & 4815 & 24.3 & 2109 & 3372 & 0.038 & 5.10 & $2.78 \mathrm{E}+06$
\end{tabular}
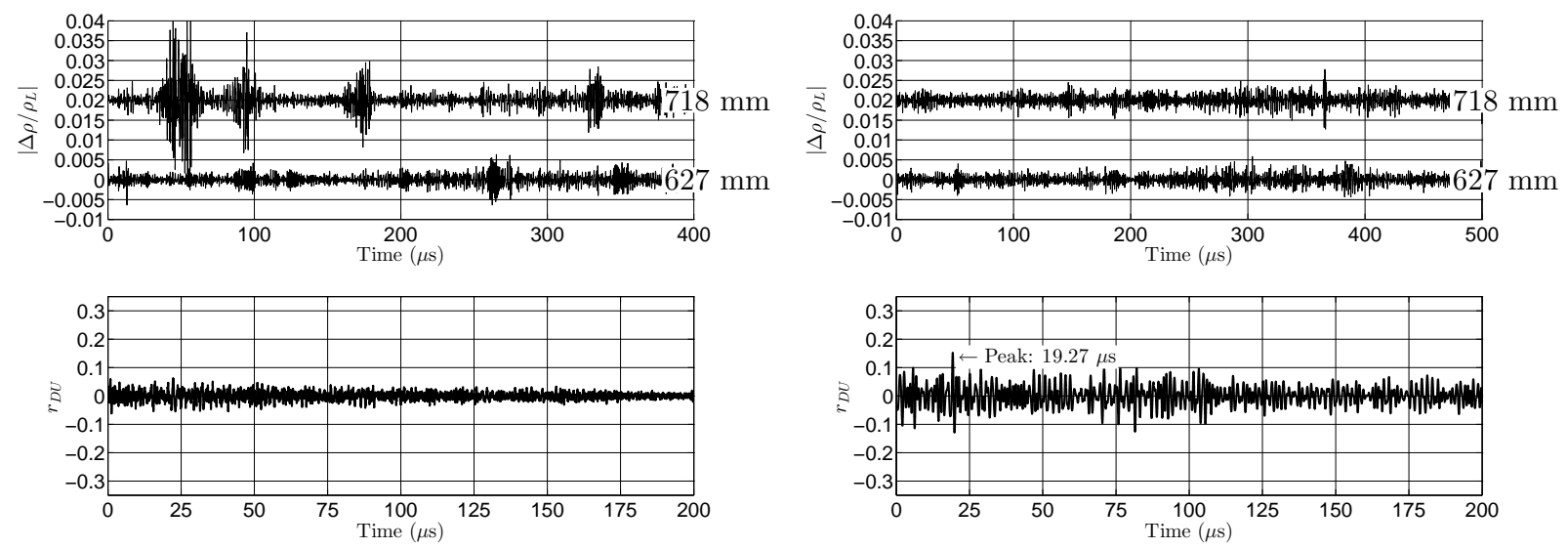

(a) Shot 2769: $R e_{E}^{U n i t}=5.18 \mathrm{E} 6(1 / \mathrm{m})$

(b) Shot 2781: $\operatorname{Re}_{E}^{U n i t}=2.78 \mathrm{E} 6(1 / \mathrm{m})$

Figure 12. Time traces and cross-correlations of $\Delta \rho / \rho_{L}$ for the high enthalpy shots (conditions summarized in Table 5).

Table 6. Boundary layer scaling for the high enthalpy shot series (conditions summarized in Table 5.

\begin{tabular}{cccccccccc} 
Shot & $\begin{array}{c}U_{E} \\
(\mathrm{~m} / \mathrm{s})\end{array}$ & $\begin{array}{c}\tau \\
(\mu \mathrm{s})\end{array}$ & $\begin{array}{c}\tau / \Delta s \\
(\mathrm{~m} / \mathrm{s})\end{array}$ & $\begin{array}{c}\delta_{U} \\
(\mu \mathrm{m})\end{array}$ & $\begin{array}{c}f_{U} \\
(\mathrm{kHz})\end{array}$ & $\begin{array}{c}2 f_{U} \delta_{U} / U_{E} \\
(-)\end{array}$ & $\begin{array}{c}\delta_{D} \\
(\mu \mathrm{m})\end{array}$ & $\begin{array}{c}f_{D} \\
(\mathrm{kHz})\end{array}$ & $\begin{array}{c}2 f_{D} \delta_{D} / U_{E} \\
(-)\end{array}$ \\
\hline 2769 & 4060 & - & - & 1160 & 1290 & 0.74 & 1250 & - & - \\
2781 & 4820 & 19.3 & 4720 & 1690 & 1130 & 0.79 & 1800 & 980 & 0.73
\end{tabular}



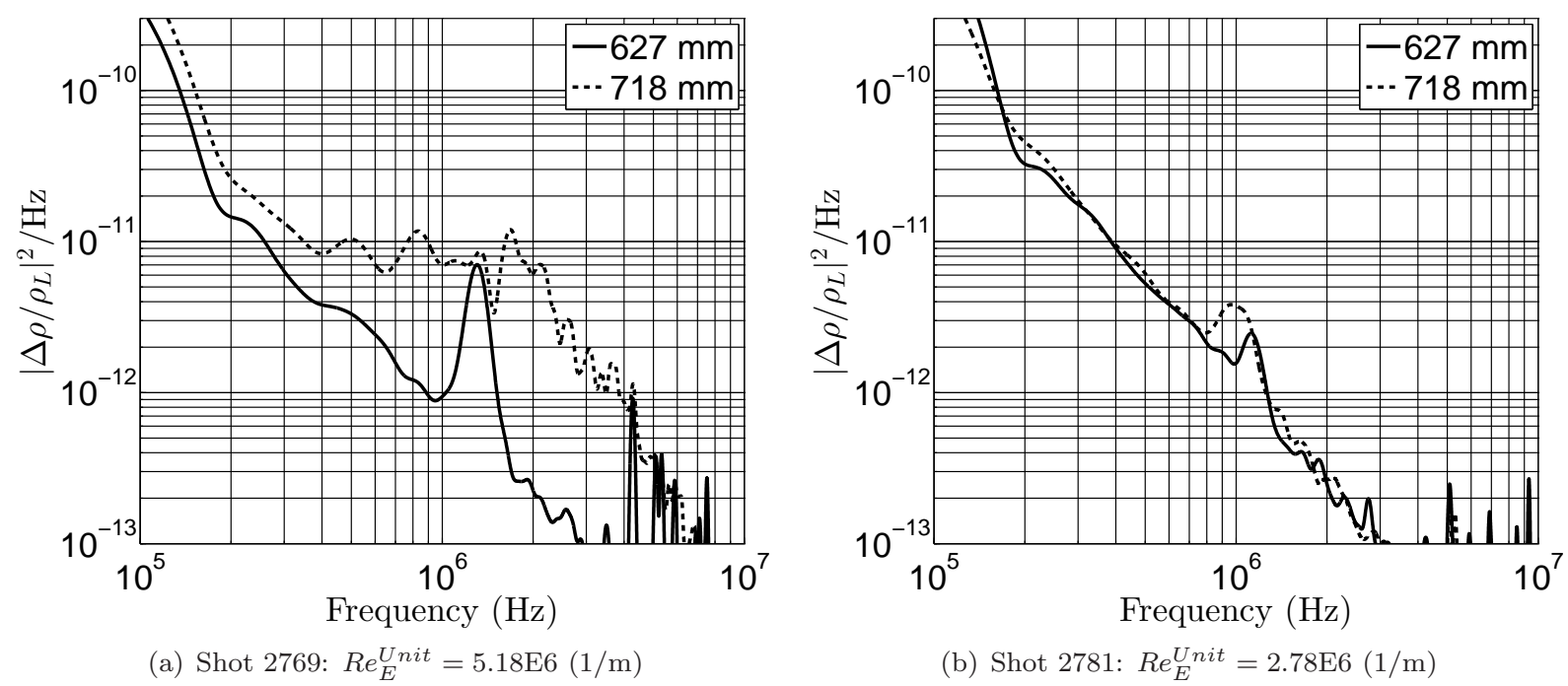

Figure 13. Power spectral density estimates of $\Delta \rho / \rho_{L}$ for the $\mathbf{N}_{2}$ shot series (conditions summarized in Table 5).

\section{Conclusion}

The FLDI was used to investigate disturbances in a hypervelocity boundary layer on a sharp five degree half-angle cone. Two sensitive FLDI probe volumes were aligned along a generator of the cone that recorded time-traces of density fluctuation at sufficient time resolution, spatial resolution, and signal to noise ratio. To measure the instability waves, the probe volumes are located just upstream of departure from laminar surface heat-flux rates. The surface heat flux rates are measured by surface mounted heat-transfer gauges. ${ }^{36,37}$

This arrangement of the FLDI allowed for the interpretation of disturbances at two points and the correlation between them. When both the upstream and downstream band-pass filtered time-traces of $\Delta \rho / \rho_{L}$ show low-amplitude, wave packet like behavior, a peak in cross-correlation is detected at a time-lag nearly consistent with the edge-velocity, spatial-separation time scale. This implies that the detectors are tracking wave packets that are traveling along the generator of the cone at approximately the edge velocity. This observation is made in air and $\mathrm{N}_{2}$ at moderate run conditions, and also demonstrated at high-enthalpy conditions for a single case in $\mathrm{N}_{2}$.

Distinct peaks in the spectral response at several frequencies (in a range of $500 \mathrm{kHz}$ to $1.3 \mathrm{MHz}$ ) are consistent with estimates of the acoustic instability. The frequency of the spectral peak at the upstream detector was observed to be higher than the frequency of the spectral peak at the downstream detector. The frequency is inversely proportional to the computed boundary layer thickness. For some cases, the spectral content is observed to broaden significantly. The growth in amplitude and the broadening of frequency content are consistent with departures from the laminar surface heating-rate, suggesting that the excitation and growth of the acoustic instability play an essential role in the transition process.

High-speed schlieren cinematography also appears to capture the instability. Moderate resolution images of the instability are recorded with a high-speed camera (150k to $300 \mathrm{k}$ frames per second), and a short pulse duration (12 ns) light source. The images show the structures of the instability to be inclined at a 13-26 deg angle to the surface.

For selected cases, amplification factors are calculated from the power spectral density estimates to assess how the wave packets are increasing in amplitude between the upstream and downstream probe volumes. The maximum amplification factor was observed to be $N \approx 0.5-0.9$ for the detector spacing $\Delta s=91 \mathrm{~mm}$. This is similar to the order of magnitude of maximum growth rates computed by linear stability theory. ${ }^{44}$ Preliminary analysis indicates no significant difference between $\mathrm{N}_{2}$ and air boundary layer disturbance amplification factors for the representative cases. Computation of acoustic damping by thermo-chemical relaxation processes is presented for the same representative cases, and indicates that there is a negligible amount of absorption for both air and $\mathrm{N}_{2}$ at the observed disturbance frequencies. 


\section{Acknowledgments}

Thanks to Bahram Valiferdowsi of GALCIT for the isometric views of the solid model of the facility, and helping run it. Special thanks to Dr. Ross Wagnild of Sandia National Laboratories for performing the grid generation and general help with the computations. Thanks to Jason Damazo of GALCIT for his helpful discussions on high-speed imaging. Also, thanks to Joe Jewell for instrumenting the cone with high-speed thermocouples. This work was sponsored by AFOSR/National Center for Hypersonic Research in Laminar-Turbulent Transition, for which Dr. John Schmisseur and Dr. Deepak Bose are the program managers. The views and conclusions contained herein are those of the authors and should not be interpreted as necessarily representing the official policies or endorsements, either expressed or implied, of the Air Force Office of Scientific Research or the U.S. Government.

\section{References}

\footnotetext{
${ }^{1}$ Germain, P., The Boundary Layer On a Sharp Cone in High-enthalpy Flow, Ph.D. thesis, California Institute of Technology, California, 1993.

${ }^{2}$ Germain, P. D. and Hornung, H. G., "Transition on a Slender Cone in Hypervelocity Flow," Experiments in Fluids, Vol. 22, 1997, pp. 183-190.

${ }^{3}$ Adam, P., Enthalpy Effects on Hypervelocity Boundary Layers, Ph.D. thesis, California Institute of Technology, California, 1997.

${ }^{4}$ Adam, P. H. and Hornung, H. G., "Enthalpy Effects on Hypervelocity Boundary-layer Transition: Ground Test and Flight Data," Journal of Spacecraft And Rockets, Vol. 34, No. 5, SEP-OCT 1997, pp. 614-619.

${ }^{5}$ Rasheed, A., Passive Hypervelocity Boundary Layer Control Using an Acoustically Absorptive Surface, Ph.D. thesis, California Institute of Technology, California, 2001.

${ }^{6}$ Fujii, K., An Experimental Investigation of the Attachment Line Boundary-Layer Transition on Swept Cylinders in Hypervelocity Flow, Ph.D. thesis, University of Tokyo, California, 1993.

${ }^{7}$ Rasheed, A., Hornung, H. G., Fedorov, A. V., and Malmuth, N. D., "Experiments on Passive Hypervelocity Boundarylayer Control Using an Ultrasonically Absorptive Surface," AIAA J., Vol. 40, No. 3, MAR 2002, pp. 481-489.

${ }^{8}$ Demetriades, A., "An Experiment On The Stability Of Hypersonic Laminar Boundary Layers," Journal of Fluid Mechanics, Vol. 7, No. 3, 1960, pp. 385-396.

${ }^{9}$ Demetriades, A., "Hypersonic Viscous Flow Over a Slender Cone. III - Laminar Instability and Transition," Proceedings of the 7th AIAA Fluid and Plasma Dynamics Conference, No. AIAA 74-535, AIAA, Palo Alto, California, 1974.

${ }^{10}$ Kendall, J. M., "Wind-Tunnel Experiments Relating to Supersonic and Hypersonic Boundary-Layer Transition," AIAA Journal, Vol. 13, No. 3, 1975, pp. 290-299.

${ }^{11}$ Stetson, K. F., Donaldson, J. C., and Siler, L. G., "Laminar Boundary Layer Stability Experiments on a Cone at Mach 8, Part 2: Blunt Cone," Proceedings of the 22nd AIAA Aerospace Sciences Meeting, No. AIAA 84-0006, AIAA, Reno, Nevada, 1984.

${ }^{12}$ Stetson, K. and Kimmel, R. L., "On Hypersonic Boundary-layer Stability," Proceedings of the 13th Aerospace Sciences Meeting and Exhibit, AIAA, Reno, NV, 1992.

${ }^{13}$ Roediger, T., Knauss, H., Estorf, M., Schneider, S. P., and Smorodsky, B. V., "Hypersonic Instability Waves Measured Using Fast-Response Heat-Flux Gauges," Journal of Spacecraft And Rockets, Vol. 46, No. 2, MAR-APR 2009, pp. $266-273$.

${ }^{14}$ Tanno, H., Komura, T., Sato, K., Itoh, K., Takahashi, M., and Fujii, K., "Measurements of Hypersonic Boundary Layer Transition on Cone Models in the Free-Piston Shock Tunnel HIEST," Proceedings of 47th AIAA Aerospace Sciences Meeting including The New Horizons Forum and Aerospace Exposition, AIAA, Orlando, FL, 2009.

${ }^{15}$ Heitmann, D., Kähler, C., Radespiel, R., Rödiger, T., Knauss, H., and Wagner, S., "Non-Intrusive Generation of Instability Waves in a Planar Hypersonic Boundary Layer," Experiments in Fluids, Vol. 50, August 2011, pp. $457-464$.

${ }^{16}$ Keisuke, F., Noriaki, H., Tadao, K., Shoichi, T., Muneyoshi, N., Yukihiro, I., Akihiro, N., and Hiroshi, O., "A Measurement of Instability Wave in the Hypersonic Boundary Layer on a Sharp Cone," Proceedings of the 41st AIAA Fluid Dynamics Conference and Exhibit, No. AIAA 2011-3871, AIAA, Honolulu, Hawaii, 2011.

${ }^{17}$ Parziale, N. J., Jewell, J. S., Shepherd, J. E., and Hornung, H. G., "Optical Detection of Transitional Phenomena on Slender Bodies in Hypervelocity Flow," Proceedings of AVT-200 Specialists' Meeting on Hypersonic Laminar-Turbulent Transition, NATO, San Diego, California, 2012.

${ }^{18}$ Parziale, N. J., Jewell, J. S., Shepherd, J. E., and Hornung, H. G., "Shock Tunnel Noise Measurement with Resonantly Enhanced Focused Schlieren Deflectometry," Proceedings of the 28th International Symposium on Shock Waves, ISSW, Manchester, UK, 2011.

${ }^{19}$ Parziale, N. J., Shepherd, J. E., and Hornung, H. G., "Reflected Shock Tunnel Noise Measurement by Focused Differential Interferometry," Proceedings of 42nd AIAA Fluid Dynamics Conference and Exhibit, AIAA, New Orleans, Louisiana, 2012.

${ }^{20}$ Parziale, N. J., Shepherd, J. E., and Hornung, H. G., "Differential Interferometric Measurement of Instability in a Hypervelocity Boundary Layer," AIAA J., TBD, pp. In Press.

${ }^{21}$ Hornung, H. G., "Performance Data of the New Free-Piston Shock Tunnel at GALCIT," Proceedings of 17th AIAA Aerospace Ground Testing Conference, AIAA, Nashville, TN, 1992.

${ }^{22}$ Goodwin, D. G., "An Open-Source, Extensible Software Suite for CVD Process Simulation," Electrochemical Society, 2003, pp. 155-162.
} 
${ }^{23}$ Browne, S., Ziegler, J., and Shepherd, J. E., "Numerical Solution Methods for Shock and Detonation Jump Conditions," GALCIT - FM2006-006, 2006.

${ }^{24}$ Gordon, S. and McBride, B., "Thermodynamic Data to 20000 K for Monatomic Gases," NASA TP-1999-208523, 1999.

${ }^{25}$ McBride, B., Zehe, M. J., and Gordon, S., "NASA Glenn Coefficients for Calculating Thermodynamic Properties of Individual Species," NASA TP-2002-211556, 2002.

${ }^{26}$ Candler, G. V., "Hypersonic Nozzle Analysis Using an Excluded Volume Equation of State," Proceedings of 38th AIAA Thermophysics Conference, AIAA, Toronto, Ontario Canada, 2005.

${ }^{27}$ Wagnild, R. M., High Enthalpy Effects on Two Boundary Layer Disturbances in Supersonic and Hypersonic Flow, Ph.D. thesis, University of Minnesota, Minnesota, 2012.

${ }^{28}$ Spalart, P. R. and Allmaras, S. R., "A One-equation Turbulence Model for Aerodynamic Flows," Proceedings of $30 t h$ AIAA Aerospace Sciences Meeting and Exhibit, AIAA, Reno, Nevada, 1992.

${ }^{29}$ Catrisa, S. and Aupoix, B., "Density Corrections for Turbulence Models," Aerospace Science and Technology, Vol. 4, No. 1, 2000, pp. $1-11$.

${ }^{30}$ Johnson, H. B., Thermochemical Interactions in Hypersonic Boundary Layer Stabity, Ph.D. thesis, University of Minnesota, Minnesota, 2000.

${ }^{31}$ Johnson, H. B., Seipp, T. G., and Candler, G. V., "Numerical Study of Hypersonic Reacting Boundary Layer Transition on Cones," Physics of Fluids, Vol. 10, No. 13, October 1998, pp. 2676-2685.

${ }^{32}$ Smeets, G., "Laser Interferometer for High Sensitivity Measurements on Transient Phase Objects," IEEE Transactions on Aerospace and Electronic Systems, Vol. AES-8, No. 2, March 1972, pp. 186-190.

${ }^{33}$ Smeets, G. and George, A., "Laser Differential Interferometer Applications in Gas Dynamics," Translation of ISL Internal Report 28/73, Original 1975, Translation 1996.

${ }^{34}$ Smeets, G., "Flow Diagnostics by Laser Interferometry," IEEE Transactions on Aerospace and Electronic Systems, Vol. AES-13, No. 2, March 1977, pp. 82-90.

${ }^{35}$ Siegman, A. E., Lasers, University Science Books, 1986.

${ }^{36}$ Jewell, J. S., Leyva, I. A., Parziale, N. J., and Shepherd, J. E., "Effect of Gas Injection on Transition in Hypervelocity Boundary Layers," Proceedings of the 28th International Symposium on Shock Waves, ISSW, Manchester, UK, 2011.

${ }^{37}$ Jewell, J. S., Parziale, N. J., Leyva, I. A., Shepherd, J. E., and Hornung, H. G., "Turbulent Spot Observations within a Hypervelocity Boundary Layer on a 5-degree Half-Angle Cone," Proceedings of 42nd AIAA Fluid Dynamics Conference and Exhibit, AIAA, New Orleans, Louisiana, 2012.

${ }^{38}$ Mack, L. M., "Linear Stability Theory and the Problem of Supersonic Boundary-layer Transition," AIAA, Vol. 13, No. 3, July 1975 , pp. $278-289$.

${ }^{39}$ Fedorov, A., "Transition and Stability of High-Speed Boundary Layers," Annual Review of Fluid Mechanics, Vol. 43, August 2011, pp. 79-95.

${ }^{40}$ Settles, G. S., Schlieren and Shadowgraph Techniques, Springer-Verlag Berlin Heidelberg, First ed., 2001.

${ }^{41}$ VanDercreek, C. P., Hypersonic Application of Focused Schlieren and Deflectometry, Ph.D. thesis, University of Maryland, College Park, Maryland, 2010.

${ }^{42}$ Laurence, S. J., Wagner, A., Hannemann, K., Wartemann, V., Lüdeke, H., Tanno, H., and Itoh, K., "Time-Resolved Visualization of Instability Waves in a Hypersonic Boundary Layer," AIAA, Vol. 50, No. 6, 2012, pp. $243-246$.

${ }^{43}$ White, F., Viscous Fluid Flow, McGraw-Hill, 2nd ed., 1991.

${ }^{44}$ Malik, M. R. and Spall, R. E., "On the Stability of Compressible Flow Past Axisymmetric Bodies," Journal of Fluid Mechanics, Vol. 228, pp. 443-463.

${ }^{45}$ Kline, S. J. and McClintock, F. A., "Describing Uncertainties in Single Sample Experiments," Mechanical Engineering, Vol. 75, 1953, pp. 3-8.

${ }^{46}$ Beckwith, T. G., Marangoni, R. D., and Lienhard, J. H., Mechanical Measurements, Pearson-Prentice Hall, Sixth ed., 2007.

${ }^{47}$ Fujii, K. and Hornung, H. G., "A Procedure to Estimate the Absorption Rate of Sound Propagating Through High Temperature Gas," GALCIT Report FM 2001.004, 2001.

${ }^{48}$ Fujii, K. and Hornung, H. G., "Experimental Investigation of High-Enthalpy Effects on Attachment-Line Boundary-Layer Transition," AIAA, Vol. 41, No. 7, July 2003, pp. 1282-1291.

${ }^{49}$ Dorrance, W. H., Viscous Hypersonic Flow, McGraw-Hill, 1962. 